\title{
WILEY-VCH
}

DOI: 10.1002/ ((please add manuscript number))

Article type: Full Paper

\section{Improvement in the Electrical Properties of Nickel Plated Steel using Graphitic Carbon Coatings}

Christopher A. Mills, * Erdni Batyrev, Maurice J. R. Jansen, Muhammad Ahmad, Tanveerkhan S. Pathan, Elizabeth J. Legge, Digvijay B. Thakur, Samson N. Patole, Dan J. L. Brett, Paul R. Shearing, Hans van der Weijde, and S. Ravi P. Silva

\section{Dr. C. A. Mills}

Tata Steel, Research and Development, Swansea Technology Centre, Swansea, SA2 8PP, UK E-mail: Christopher.Mills@tatasteeleurope.com

Dr. C. A. Mills, Dr. M. Ahmad, E. J. Legge, Prof. S. R. P. Silva

Advanced Technology Institute, University of Surrey, Guildford, GU2 7XH, UK

Dr. E. Batyrev, M. J. R. Jansen, Dr. H. van der Weijde

Tata Steel, Research and Development, Ijmuiden Technology Centre, PO BOX 10000, 1970CA IJmuiden, the Netherlands

Dr. T. S. Pathan, Prof. Dan J. L. Brett, Prof. P. R. Shearing

Electrochemical Innovation Laboratory, Department of Chemical Engineering, University

College London, Torrington Place, London WC1E 7JE, UK

E. J. Legge

National Physical Laboratory, Hampton Road, Teddington, Middlesex, TW11 0LW, UK

Dr. D. B. Thakur, Dr. S. N. Patole

Tata Steel, Research and Development, Warwick Technology Centre, 9 Sir William Lyons

Road, Coventry, CV4 7EZ, UK

Keywords: nickel plated steel, coatings, graphitic carbon, photothermal chemical vapour deposition, electrical properties

Thin layers of highly conductive graphitic carbon have been deposited onto nickel plated steel substrates using a direct photothermal chemical vapour deposition (PTCVD) technique. The coated nickel plated steel substrates have improved electrical properties (sheet resistance and interfacial contact resistance) compared to the pristine nickel plated steel, which makes it a cost effective alternative to stainless steel for steel producers to use in high-end electrical applications such as energy storage and microelectronics. The coated nickel plated steel has been found to have an approximately $10 \%$ reduction in sheet resistance, and a 200 times reduction in interfacial contact resistance (under compression at $140 \mathrm{~N} \mathrm{~cm}^{-2}$ ), compared to the pristine nickel plated steel. The interfacial contact resistance is also three times lower than that of a benchmark gold coated stainless steel equivalent at the same pressure. 


\section{WILEY-VCH}

\section{Introduction}

When it comes to electrical conductivity, metals stand out as being the materials of choice for applications requiring high electrical charge transfer. Indeed, until recently, the most conducting metal, silver (approx. $6 \times 10^{7} \mathrm{~S} \mathrm{~m}^{-1}$ ), could be considered to have an electrical conductivity almost 300 times that of the nearest conducting non-metal, carbon in the form of graphite (with a basal plane conductivity of approx. $2 \times 10^{5} \mathrm{~S} \mathrm{~m}^{-1}\left[\right.$ at $\left.20^{\circ} \mathrm{C}\right]$ ). ${ }^{[1]}$ However, lately, the discovery of ballistic conduction in single sheets of graphene has improved the electrical conduction in carbon to approx. $10^{8} \mathrm{~S} \mathrm{~m}^{-1}$, and has revitalized interest in the use of carbon for electrical charge transport. ${ }^{[2]}$ Indeed, when it comes to conduction properties, carbon reveals its versatility through the electrical charge transfer performance of the different carbon allotropes: ranging from the ballistic conductive properties of graphitic carbons (such as graphene and carbon nanotubes), to the insulating properties of diamond (approx. $10^{-13} \mathrm{~S}$ $\mathrm{m}^{-1}$ ), and values in-between for amorphous- and diamond-like carbons. ${ }^{[1]}$ The addition of functionality to a carbon analogue, such as the introduction of oxygen to produce graphene oxide, can be used as required to further tune the electrical properties. ${ }^{[3]}$

In this way, carbon has been developed for a number of applications involving electrical conduction, including for example electrically conducting textiles ${ }^{[5]}$ and inks ${ }^{[6]}$. Graphitic carbon bipolar plates have also been used in electrochemical fuel cells, ${ }^{[4]}$ however carbon suffers from some disadvantages when it comes to its utilization in these types of application. For example, carbon alone pressed into a 3-dimensional form is relatively brittle, is not malleable nor ductile, and cannot be produced in robust, thin structures. This may be overcome to some extent by the introduction of polymer binders, which assist in forming the carbon into 3-D shapes. ${ }^{[7]}$ However this can be to the detriment of the electrical conductivity as typically the low electrical conductivity polymer binder interferes with the natural 


\section{WILEY-VCH}

electrical conductivity of the carbon, although recent developments have improved polymer composites allowing them to retain electrical conductivity. ${ }^{[7]}$

This problem may also be overcome if the carbon can be introduced onto a solid support with similarly high electrical conductivity, such as a metal, which consequently has less impact on the electrical conductivity of the carbon. In this way, the metallic support material can be formed into wires, thin 2-D sheets, or 3-D structures (such as meshes) onto which the carbon can be deposited, allowing for its use in traditional and more contemporary electrical conduction applications. Post forming, the most efficient methods to apply a conformal coating on complex 3-dimensional shapes is via either the liquid or gas phases. Although less common, a carbon layer can be deposited from the liquid phase using electrodeposition, ${ }^{[8]}$ however the technique typically requires high voltages and liquid environments which make it difficult for scale up. More common is to deposit carbon materials from the gas phase, and a wide variety of carbon allotropes can be controllably grown on various conducting and nonconducting substrates using techniques such as chemical vapor deposition. ${ }^{[9]}$ Chemical vapor deposition of carbon coatings has advantages in providing conformal coverage over complex shapes, high purity growth on a variety of metallic substrates and relatively low gas feedstock utilization and waste. ${ }^{[10]}$ PTCVD in particular has the advantage of allowing rapid controllable application of temperature by utilizing light energy. ${ }^{[11]}$

Substrates for electrical applications should be mechanically ductile to allow for forming, should be strong to avoid deformation, should not relax over time, and should be wear resistant with high environmental stability to avoid corrosion. Typically, when considering steels, mild steel and stainless steel are potential substrates. Mild steel has good electrical conductivity (approx. $10^{7} \mathrm{~S} \mathrm{~m}^{-1}$ ) but is unfortunately prone to corrosion. On the other hand, due to a thick oxide layer on its surface stainless steel has excellent corrosion resistance, 


\section{WILEY-VCH}

unfortunately however the same oxide layer impairs its electrical conductivity (stainless steel type $\left.304, \sigma=1.4 \times 10^{6} \mathrm{~S} \mathrm{~m}^{-1}\right) \cdot{ }^{[12]}$ For steel producers, nickel plated steel offers a cost-effective alternative to stainless steel. It is commonly used in the electronics, oil and gas, chemical, aerospace and automotive industries due its benefits such as corrosion resistance, increased hardness, decorative and magnetic properties. It allows for stamping and deep drawing while presenting welding and brazing properties superior to those of stainless steel. It also forms a good basis for chrome piece-plating - reducing the need for processing steps such as postplating and pre-polishing. Here we utilize the excellent catalytic carbon growth properties of nickel to present a method for the application of graphitic carbon coatings to nickel plated steel using photothermal chemical vapor deposition (PTCVD). ${ }^{[13]}$ This provides a reduction in sheet and interfacial contact resistances suitable for production of high electrical conductivity materials, in a number of different form factors, for a variety of applications.

\section{Surface characterization}

Raman spectroscopy of the nickel-coated steel substrate is undertaken post-graphitic carbon deposition (Figure 1), showing prominent D- and G-peaks at 1347 and $1584 \mathrm{~cm}^{-1}$ respectively, and a smaller 2D- (or G'-) peak at $2694 \mathrm{~cm}^{-1}$. For comparison, the spectra of HOPG and diamond have prominent peaks at $1582 \mathrm{~cm}^{-1}$ and $1335 \mathrm{~cm}^{-1}$ respectively (Figure 1), ${ }^{[14]}$ due to the respective $\mathrm{sp}^{2}$ and $\mathrm{sp}^{3}$ carbon contents. According to the phase change diagram of carbon, ${ }^{[15]}$ the processing conditions used in our experiments $\left(267 \mathrm{~Pa}\right.$ and approx. $750{ }^{\circ} \mathrm{C}$ $[1,023 \mathrm{~K}])$ suggest that the carbon growth should be predominantly graphitic in nature, with insufficient temperature and pressure to produce metastable diamond structures in the graphitic thin film.

The G-peak in the Raman spectra (Figure 1) is due to an in-plane vibrational mode of the $\mathrm{sp}^{2}$ hybrid carbon atoms in the carbon layer. The more intense the G-peak, when compared to the 


\section{WILEY-VCH}

2D- peak, the more likely that the carbon is graphitic (multilayer) in structure. A single layer of graphene would normally have an $\mathrm{I}_{2 \mathrm{D}} / \mathrm{I}_{\mathrm{G}}$ ratio of $2 .{ }^{[16]}$ This effect is usually accompanied with a shift in the 2D-peak position from approx. $2680 \mathrm{~cm}^{-1}$ to $2720 \mathrm{~cm}^{-1} .^{[16]}$ The position and intensity of the 2D- peak in Figure 1 therefore suggests that the carbon nanomaterial grown here is multilayer and graphitic in nature, and can be used to estimate the number of layers of graphitic material. A single layer of graphene will produce a peak with a full width at half maximum (FWHM) of approx. $30 \mathrm{~cm}^{-1}$. Successive layers cause the 2D-peak to be split into overlapping modes. ${ }^{[16]}$ Again, the FWHM $\left(74 \mathrm{~cm}^{-1}\right)$ and peak maximum $\left(2694 \mathrm{~cm}^{-1}\right)$ of the 2D-peak (Table 1) suggests that the carbon is multilayer.

The average $\mathrm{sp}^{2}$ cluster size (La) was calculated using values for $\mathrm{C}$ and $\mathrm{C}$ ' suggested in literature for a Raman laser wavelength of $514.5 \mathrm{~nm}\left(\mathrm{C}=44 \AA, \mathrm{C}^{\prime}=0.0055 \AA\right) .{ }^{[17]}$ For an $\mathrm{I}_{\mathrm{D}} / \mathrm{I}_{\mathrm{G}}$ ratio of 0.85 , the equation $\mathrm{I}_{\mathrm{D}} / \mathrm{I}_{\mathrm{G}}=\mathrm{C}^{\prime}(\lambda) \mathrm{La}^{\prime 2}$, as proposed by Ferrari and Robertson, suggests an average $\mathrm{sp}^{2}$ cluster size of $1.25 \mathrm{~nm}$, while the Tuinstra and Koenig (TK) equation $\left(\mathrm{I}_{\mathrm{D}} / \mathrm{I}_{\mathrm{G}}=\mathrm{C}(\lambda) / \mathrm{La}\right)^{[18]}$ returns an average $\mathrm{sp}^{2}$ cluster size of $5.17 \mathrm{~nm}$. With a FWHM $>40 \mathrm{~cm}^{-1}$, La' can be considered a more accurate reflection of the inter-defect distance, suggesting a defective carbon layer; a conclusion supported by the high $\mathrm{I}_{\mathrm{D}} / \mathrm{I}_{\mathrm{G}}$ ratio.

XPS analysis of the graphitic carbon layer grown on the nickel plated steel (Figure 2) reveals that no species other than nickel, carbon and oxygen is present, indicating the high purity of the CVD graphene coating on the nickel plated steel. The graphitic carbon layer produces a dominant $\mathrm{sp}^{2}$ hybridization peak in the XPS C1s spectra which is comparable with pure graphene exfoliated from a highly oriented pyrolytic graphite (HOPG) standard. The O1s and Ni2p spectra show that although localized oxidation occurs on the pristine nickel surface at the edges of the graphene flakes, a dominant nickel metal contribution of $70 \%$ is present as compared to the $\left[\mathrm{NiO}+\mathrm{Ni}(\mathrm{OH})_{2}\right]$ content at $30 \%$. Consequently, electron transport 


\section{WILEY-VCH}

preferentially progresses through the metallic nickel which influences the overall conductivity. The analysis of the underlying nickel surface demonstrates that metallic nickel is the dominant species, suggesting that the graphitic carbon layer acts as a layer of oxidation protection for the metallic surface. ${ }^{[19]}$

An SEM image of the oxidized surface of the nickel plated steel (Figure 3a) displays a uniform surface structure with fine grains of nickel oxide (approx. $50 \mathrm{~nm}$ diameter) and a low roughness. In comparison, SEM images of the carbon coated nickel plated steel surface (Figure 3b) reveal a surface structure consisting of large domains above the nickel grain structure with clear grain boundaries, up to $1 \mu \mathrm{m}$ in diameter, and with further corrugated structuring incorporated within some of these domains. The coating looks to be mostly uniform, although there are thicker carbon flakes in the coating as evidenced by the darker areas to the right of Figure $3 b$.

A patchy network of the graphene flakes was found on the rear of the nickel plated steel strip while the front has a more homogeneous distribution of the graphene flakes (Figure $3 \mathrm{c}$ and $d$ ). Most likely this difference was caused by the geometry of the CVD process where front of the substrate was facing the heating lamps in the CVD apparatus. This may be mitigated in future by the use of multiple heating lamps to produce uniform heating around the substrate which will allow a more uniform coating. Therefore electrical conductivity measurements and XPS characterization were performed on the front surface where the graphitic carbon layer is more homogeneously distributed over the nickel surface.

A closer examination of the corrugated structures (Figure 4) within a single domain of the carbon coating shows that the corrugation resembles a terracing indicative of crystal growth at an acute angle to the steel surface. Domains in which these terraces are visible can be found 


\section{WILEY-VCH}

neighboring each other, although the direction of terracing is different in neighboring domains, indicative of crystallization mechanisms wherein the angle of growth at crystal nucleation is different. Domains in other areas display no terracing.

Domain structures have previously been seen in the CVD production of graphitic carbon, particularly through a columnar growth mechanism. ${ }^{[1]}$ Obraztsov and coworkers ${ }^{[20]}$ observed the production of planar micrometer dimensioned domains, separated by ridges of nanometer width, in the deposition of thin carbon films on nickel substrates. The authors describe a growth mechanism that involves both well-ordered graphitic carbon and disordered amorphous carbon, facilitated by a good lattice match between the nickel and graphene (assuming a polycrystalline nickel surface with a [111] lattice structure). They then attributed the features to multi-graphene layer carbon growth over the substrate surface with the ridges between domains formed as the substrate was cooled, causing the carbon layer to "buckle" upwards due to the differences in thermal expansion coefficients of the carbon and the underlying nickel.

Here, the appearance of flat domains in some regions of the carbon coating but terracing on individual domains in other areas suggests that a similar mechanism may be taking place. Obraztsov and coworkers produced carbon films using CVD activated by DC discharge of a hydrogen:methane $\left(\mathrm{CH}_{4}\right)$ process gas at 80 Torr and $950{ }^{\circ} \mathrm{C}(1,223 \mathrm{~K})$. The time for deposition was limited to 5-10 minutes to produce the required thin films. The higher process temperature $\left(950^{\circ} \mathrm{C}\right)$ used for the $\mathrm{DC}$ discharge method is required as methane requires a higher cracking temperature than the acetylene used in this work, ${ }^{[1]}$ as evidenced by previous literature. ${ }^{[21]}$ 


\section{WILEY-VCH}

The SEM images (Figure 3) suggest that crystal growth of the graphitic carbon proceeds in a mechanism similar to that suggested by Obraztsov and coworkers, where columns of graphitic carbon are produced on the surface, with the graphite basal plane parallel to the surface. The low temperature $\left(750^{\circ} \mathrm{C}\right) \mathrm{PTCVD}$ deposition will favor columnar growth, despite the high carbon/hydrogen feedstock ratio (1:11) used, which, although it is used to reduce gas phase nucleation and growth, tends to favor laminar growth on the surface. ${ }^{[1]}$ However, whereas the domains produced by the DC discharge method are predominantly aligned parallel to the substrate surface, the presence of the domain terraces in distinct areas of the PTCVD deposited carbon coating suggests that nucleation and growth in some of the domains occurs at angles acute to the surface, possibly due to imperfect convex growth over substrate defects. ${ }^{[1]}$ Such imperfect convex growth maybe further exacerbated when the substrate shrinks on cooling, ${ }^{[20]}$ causing stress fractures in the carbon coating.

Previously, CVD graphene grown epitaxially on nickel metal has shown that the terminal bonds at the graphene edges are very reactive and can chemisorb to oxidised nickel $\left[\mathrm{Ni}(\mathrm{OH})_{2} / \mathrm{NiO}\right]$ surfaces, ${ }^{[22]}$ strengthening the adhesion of the carbon layers to the nickel surface. This $\mathrm{C}-\mathrm{O}$ bonding (see figure 2) can also limit oxygen diffusion along the Ni surface. Adhesive tape pull-off tests show that the graphitic carbon is relatively well adhered to the substrate with only small patches of the carbon released from the surface (as evidenced by Raman spectroscopy of the tape surface).

\section{Electrical characterization}

The terracing has subsequently been found to have an effect on the electrical properties of the carbon coated nickel plated steel. The sheet resistance $\left(\mathrm{R}_{\mathrm{sh}}\right)$ of an uncoated nickel plated steel reference and a graphitic carbon coated nickel plated steel substrate were estimated using 4point probe measurements and compared with that for bare stainless steel. The comparative 


\section{WILEY-VCH}

current-voltage graph is given in Figure 5. Additionally, the interfacial contact resistance (ICR) of the samples has been plotted for a range of applied areal pressures $\left(\mathrm{N} \mathrm{cm}^{-2}\right)$ and compared to the Department of Energy (DOE) 2020 target for contact resistance in bipolar plates $\left(10 \mathrm{~m} \Omega \mathrm{cm}^{-2} \text { at } 140 \mathrm{~N} \mathrm{~cm}^{-2}\right)^{[23]}$ (Figure 6).

The $\mathrm{R}_{\text {sh }}$ values for the nickel plated steel are found to be less than that for the stainless steel, both on the thicker nickel plated side ( $2 \mu \mathrm{m}$ of nickel plating) and the reverse side $(0.6 \mu \mathrm{m}$ of nickel plating) (Table 2). With the application of the graphitic carbon coating, the $\mathrm{R}_{\text {sh }}$ of the nickel plated substrate further reduces to $2.52 \mathrm{~m} \Omega \square^{-1}$. Unfortunately it is not possible to separate the sheet resistances of two conducting materials using the 4-point probe method, and consequently it is not possible to calculate the effect on $\mathrm{R}_{\text {sh }}$ of the carbon coating alone. However, the measurements show that the carbon coating does increase the surface conductivity of the nickel plated steel by a substantive amount (approx. 10\%).

The uncoated stainless steel and nickel plated steel have ICR values of 388 and $61 \mathrm{~m} \Omega \mathrm{cm}^{-2}$ respectively at $140 \mathrm{~N} \mathrm{~cm}^{-2}$ (Table 3). When coated with gold, the ICR of the stainless steel decreases, to $1.01 \mathrm{~m} \Omega \mathrm{cm}^{-2}$, at the same applied pressure. Such a low ICR is considered to be a benchmark for Bipolar Plate (BPP) materials used in fuel cells. In comparison, the graphitic carbon coated nickel plated steel has an ICR of approx. $0.3 \mathrm{~m} \Omega \mathrm{cm}^{-2}$, an approx. 200 times reduction from that of the uncoated sample and a 3 times reduction from that of the benchmark gold coating. For comparison, the Department of Energy (DOE) 2020 target for contact resistance in BPPs is $10 \mathrm{~m} \Omega \mathrm{cm}^{-2}$ at $140 \mathrm{~N} \mathrm{~cm}^{-2} \cdot{ }^{[23]}$ For comparison, CVD graphene on a catalyzing nickel/stainless steel (SUS304) substrates has been produced for BPP applications with an ICR of $36 \mathrm{~m} \Omega \mathrm{cm}^{-2} .{ }^{[24]}$ Typically such coatings on stainless steel have also been examined for corrosion protection. ${ }^{[24,25]}$ 


\section{WILEY-VCH}

Pyrolytic graphite is considered to be a good electrical conductor parallel to the basal plane, but an insulator perpendicular to the basal plane. An examination of the electrical conductivity of the individual components of the graphitic carbon coated nickel plated steel

(Table 4) does not suggest that the carbon coating should improve the electrical properties of the metallic substrate. This would only occur if the carbon is graphitic, but even in this case, the graphitic carbon would have to be aligned so that electrical conduction occurs in the direction parallel to the basal plane. The results described previously suggest that the coating on the nickel-plated steel is graphitic and the basal plane is aligned either parallel to the substrate surface, or oriented at an acute angle to the surface. The latter, non-parallel orientations of the graphitic crystal grains present the more electrically conductive edges of the graphite layers to the upper surface of the coating. As such, the conductivity through the carbon film can be improved over the case where the crystals are aligned parallel to the substrate.

As mentioned, it is surprising that the carbon coating improves on the electrical conductivity of the nickel plated steel, and improves the interfacial contact resistance to an extent that it improves on that of the benchmark gold plated stainless steel. The improvement in sheet resistance may be explained by examining the conductivity of the materials and comparing them with literature values (Table 4). In this case, the measured conductivity values for the stainless steel and nickel plated steel are an order of magnitude smaller than those reported in the literature, which is expected as the experimental samples are presumed to have an oxide layer due to atmospheric exposure. The graphitic carbon coated nickel plated steel is more conductive than the other uncoated steels used in the experiments, but less conductive than the literature values for those steels. However, the conductance of the graphitic carbon coated nickel plated steel is higher than that for pure graphite, suggesting that the sheet resistance is improved by the incorporation of graphene-like conducting channels through the carbon layer 


\section{WILEY-VCH}

into the underlying unoxidized steel. In the uncoated, oxidized steel $\mathrm{R}_{\mathrm{sh}}$ is mainly measured through the surface oxide layer (Figure 7a), whereas in the carbon coated steel, where the oxide layer is removed during CVD deposition of the carbon, $\mathrm{R}_{\mathrm{sh}}$ is predominately measured through higher conductivity unoxidized steel, although there may be some resistivity due to oxidation occurring under defects in the carbon coating (Figure $7 \mathrm{~b}$ ).

Electrical conduction is even more pronounced when looking at the ICR measurements. In this case, the conductivity through the carbon coated nickel plated steel is higher than that of a gold plated stainless steel analogue. In the former, the lack of an oxide layer under the carbon coating facilitates conduction through the nickel plated steel (Figure 7d), whereas the native oxide of the stainless steel creates an impediment for current flow through the gold coated analogue (Figure 7c). This may also explain the higher ICR for graphene coated stainless steel mentioned earlier. ${ }^{[24]}$ Again, conduction through the nickel plated steel is facilitated by the misalignment of the graphitic domains with respect the surface, which promotes conduction into the nickel coating via graphene-like conduction channels.

\section{Conclusion}

The current work presents an examination of the production of graphitic carbon coatings on nickel plated steel using PTCVD, a first in the literature using this technique, revealing significant increases in both the sheet electrical conductivity and the interfacial contact resistance. We also undertake to explain the increased electrical conductivity across the graphitic carbon coating and through the coated substrate based on the angle of orientation of the graphitic carbon to the substrate, an explanation that explains the lower than expected increase in sheet conductivity (compared to e.g. a monolayer graphene coating) but also the 200 times decrease in interfacial contact resistance (where the angled graphitic domains assist electrical conduction through the nickel plated steel substrate). 


\section{WILEY-VCH}

The deposition of graphitic carbon coatings onto nickel plated steel using chemical vapor deposition has shown itself to be an efficient way of improving the electrical properties of the nickel plated steel, with a decrease in both the sheet resistance and the interfacial contact resistance: the conduction in the latter case rivals that of gold plated stainless steel. Homogeneous graphitic carbon coatings can be applied to the nickel plated steel which enhance electrical conduction and oxidation resistance. The use of nickel plated steel as the substrate presents advantages over stainless steel when it comes to the mechanical properties of the underlying steel, while offering improved corrosion protection when compared to mild steel. The ability to deposit the carbon coating on the surface of the nickel plated steel with minimal pre-treatment (amounting to a rudimentary clean with an alcohol wipe) reduces the number of process steps required to produce the coated substrate. With nickel plated steel already used in a variety of industries, ${ }^{[27]}$ the improved electrical conduction of the graphitic carbon coatings, potentially allied to their high thermal conductivity, ${ }^{[28]}$ presents a novel composite material suitable for use in electronics and energy applications.

\section{Experimental Section}

Substrates: Mirror finish nickel plated steel $(50 \mathrm{~mm}$ x $50 \mathrm{~mm}$ x $0.5 \mathrm{~mm}$, Hille and Muller GmbH., Germany), with a $2 \mu \mathrm{m}$ nickel plating on one side, and $0.6 \mu \mathrm{m}$ nickel plating on the other, was used in the PTCVD carbon deposition experiments.

PTCVD carbon deposition: PTCVD of carbon has been undertaken by carbon growth directly on to the steel surface. In this case, no additional catalyst layer was required for growth. The as-received substrates are cleaned with a methanol soaked wipe to remove any dust and grease. The CVD deposition proceeds via white light assisted PTCVD deposition of carbon, at elevated temperature. Graphitic carbon layers were deposited on the nickel plated steel 


\section{WILEY-VCH}

substrates by PTCVD using hydrogen carrier gas $(100 \mathrm{sccm})$ and acetylene $\left(\mathrm{C}_{2} \mathrm{H}_{2}\right)$ growth gas $(10 \mathrm{sccm})$ at a process pressure of $267 \mathrm{~Pa}$. The substrates were heated under approx. $4 \mathrm{~kW}$ halogen lamp power for $10 \mathrm{~min}$, prior to the introduction of the acetylene. The graphitic carbon layer was grown ( $5 \mathrm{~min}$ ) before the acetylene supply was stopped and the halogen lamps extinguished. The coated substrates were subsequently allowed to cool (15 min) to room temperature before removal.

Figure 8 gives an example of the growth process, involving 3 process steps: heating, growth and cooling. The halogen lamps are turned on $(\mathbf{A})$ and the substrates are first heated under a hydrogen atmosphere at a process pressure of approx. 2 Torr. In this case, with heating at 4 $\mathrm{kW}(50 \%)$ halogen lamp power, although the upper surface of the steel reaches approx. $725^{\circ} \mathrm{C}$, the rear of the substrate is cooled using the water-cooled sample stage and does not exceed $440{ }^{\circ} \mathrm{C}$ (Figure 8b). After heating, the growth gas (acetylene) is introduced into the chamber (B), with a consequent increase in surface temperature, although again the rear of the substrate is maintained at below $450{ }^{\circ} \mathrm{C}$. After the required growth time the halogen lamps are turned off $(\mathbf{C})$ and the acetylene valve closed. The substrates are then allowed to cool under the hydrogen atmosphere, before the chamber is purged with nitrogen gas ( $2 \times 1 \mathrm{~min})$, to remove any excess unbound hydrocarbon. The chamber is then vented and opened to allow the removal of the carbon coated steel substrates.

Characterization: The bare steel and the deposited carbon coatings have been characterized using Raman spectroscopy (DXR Raman Microscope, Thermo Scientific, USA) with a 532 $\mathrm{nm}$ laser, at $8 \mathrm{~mW}$ power, and using a $50 \mu \mathrm{m}$ pinhole which generates a spot size at the sample surface of $0.7 \mu \mathrm{m}$. For comparison, HOPG and diamond have been examined using a similar Raman microscope (Renishaw) with a $514 \mathrm{~nm}$ wavelength laser, with each spectra consisting of 2 accumulations of 10 seconds. The HOPG was analysed with a $100 \mathrm{x}$ 


\section{WILEY-VCH}

magnification lens at $0.405 \mathrm{~mW}$. The diamond was analysed with a $5 \mathrm{x}$ magnification lens at 1.9 mW. High Resolution Scanning Electron Microscopy (HR-SEM, Ultra55 FEG SEM, Zeiss) was completed using an accelerating voltage of $10 \mathrm{kV}$ and a working distance of 4-5 $\mathrm{mm}$.

XPS spectra were acquired with a Kratos ULTRA DLD instrument in hybrid mode (magnetic lens on). An aluminium-monochromated X-ray source was used at $15 \mathrm{~mA}$ and $15 \mathrm{kV}$ to generate the X-ray photons and the emitted photoelectrons were collected from an area of 0.7 $\times 0.3 \mathrm{~mm}^{2}$. The acquired raw XPS spectra were processed using CASA XPS software.

Sheet resistance $\left(\mathrm{R}_{\mathrm{sh}}\right)$ of the bare and carbon-coated nickel plated steel has been measured using a 4-point probe system (model 3007 resistivity probe, Kulicke and Soffa industries) connected to a power source and an electrometer (Keithley 2200 and 6400 respectively, Tektronix Inc., USA). Current flow is measured upon the application of voltage, in $0.1 \mathrm{~V}$ measurement steps, with the current limited at $100 \mathrm{~mA}$.

The interfacial contact resistance (ICR) has been measured, based on Ohm's law, by applying a current to the sample and measuring the potential under compressive pressure. ${ }^{[29]}$ By placing the sample between two gas diffusion layers (GDLs, untreated TGP-H-060 Toray carbon fibre papers, Fuel Cell Store, USA; electrical conductivity $(\sigma): 0.125 \mathrm{~S} \mathrm{~m}^{-1}$ through plane, $1.7 \mathrm{~S} \mathrm{~m}^{-1}$ in plane) in a compression system, the potential can be measured at different pressures dependant on the size of the sample. After a small interval (30 s), to allow for stabilisation, the potential difference is determined and used to calculate the resistance over the surface area of the sample. To calculate the ICR of the sample, several measurements are conducted on the GDLs alone, providing a reference value that is subtracted from the measurement value. The 


\section{WILEY-VCH}

sample ICR value is then divided by two to get the resistance of each interface, and multiplied by the area of the sample to provide normalised area-specific results.

Scotch tape pull-off tests were undertaken by pressing adhesive tape to the surface of the graphitic carbon coating and pulling away at angles greater than the $90^{\circ}$ from the surface at a rate of approximately $2 \mathrm{~mm} / \mathrm{s}$. Subsequently the adhesive surface of the tape was examined for the presence of the carbon coating

\section{Acknowledgements}

TP and EL acknowledge PhD support from Tata Steel and the National Physical Laboratory respectively. EL acknowledges funding provided by the National Measurement System of the U.K. Department of Business, Enterprise and Industrial Strategy and EPSRC in the UK for funding in a DOCCAT collaboration (grant numbers EP/R025304/1 \& EP/L02263X/1). CM and MA would like to thank Dr. Jose Anguita and Dr. Imalka Jayawardena (both Advanced Technology Institute, University of Surrey) for fruitful discussions regarding the production of the carbon coatings and for assistance with the completion of the sheet resistance measurements respectively. The authors also thank Dr. Keith Paton (Surface Technology Group, National Physical Laboratory) for his valuable comments with respect the manuscript.

Received: ((will be filled in by the editorial staff))

Revised: ((will be filled in by the editorial staff)) Published online: ((will be filled in by the editorial staff)) 


\section{WILEY-VCH}

References

[1] H. O. Pierson, Handbook of carbon, graphite, diamonds and fullerenes: processing, properties and applications, Noyes Publications, Park Ridge, New Jersey, U.S.A. 2012

[2] Y. Yang, C. Han, B. Jiang, J. Iocozzia, C. He, D. Shi, T. Jiang, Z. Lin, Mater. Sci. Eng., R 2016, 102, 1; Z. Mics, K.-J. Tielrooij, K. Parvez, S.A. Jensen, I. Ivanov, X. Feng, K. Müllen, M. Bonn, D. Turchinovich, Nat. Commun. 2015, 6, 7655; F. Meng, W. Lu, Q. Li, J-H. Byun, Y. Oh, T-W. Chou, Adv. Mater. 2015, 27, 35; A. S. Mayorov, R. V. Gorbachev, S. V.

Morozov, L. Britnell, R. Jalil, L. A. Ponomarenko, P. Blake, K. S. Novoselov, K. Watanabe, T. Taniguchi, A. K. Geim, Nano Lett. 2011, 11, 2396; A. K. Geim, K. S. Novoselov, Nat. Mater. 2007, 6, 183; X. Du, I. Skachko, A. Barker, E. Y. Andrei, Nat. Nano. 2008, 3, 491. [3] V. B. Mohan, R. Brown, K. Jayaraman, D. Bhattacharyya, Mater. Sci. Eng.: B 2015, 193, 49; S. Thakur, N. Karak, Carbon 2015, 94, 224; Y. Zhu, S. Murali, W. Cai, X. Li, J.W. Suk, J.R. Potts, R.S. Ruoff, Adv. Mater. 2010, 22, 3906.

[4] C. Wang, K. Xia, H. Wang, X. Liang, Z. Yin, Y. Zhang, Adv. Mater. 2018, in press, 1801072; A. Lund, N. M. van der Velden, N-K. Persson, M. M. Hamedi, C. Müller, Mater. Sci. Eng., R 2018 126, 1; A. K. Yetisen, H. Qu, A. Manbachi, H. Butt, M. R. Dokmeci, J. P. Hinestroza, M. Skorobogatiy, A. Khademhosseini, S. H. Yun, ACS Nano 2016, 10, 3042; M. Stoppa, A. Chiolerio, Sensors 2014, 14, 11957; L. Hu, M. Pasta, F. La Mantia, L. Cui, S. Jeong, H. D. Deshazer, J. W. Choi, S. M. Han, Y. Cui., Nano Lett. 2010, 10, 708.

[5] D. Li, W-Y. Lai, Y-Z. Zhang, W. Huang, Adv. Mater. 2018, 30, 1704738; N. Matsuhisa, M. Kaltenbrunner, T. Yokota, H. Jinno, K. Kuribara, T. Sekitani, T. Someya, Nat. Commun. 2015, 6, 7461; W. R. Small, M. in het Panhuis, Small 2007, 3, 1500.

[6] N. F. Asri, T. Husaini, A. B. Sulong, E. H. Majlan, W. R. W. Daud, J Hydrogen Energy 2017, 42, 9135; A. Iwan, M. Malinowski, G. Pasciak, Renew. Sustain. Energy Rev., 2015, 49, 954; A. Hermann, T. Chaudhuri, P. Spagnol, Int. J. Hydrogen Energy 2005, 30, 1297. 


\section{WILEY-VCH}

[7] K. Fu, Y. Yao, J. Dai, L. Hu, Adv. Mater. 2017, 29, 1603486; R. L. Truby, J. A. Lewis,

Nature 2016, 540, 371; E. Planes, L. Flandin, N. Alberola, Energy Procedia 2012, 20, 311.

[8] Q. Fu, J-T. Jiu, C-B. Cao, H. Wang, H-S. Zhu, Surf. Coat. Technol. 2000, 124, 196.

[9] B. Deng, Z. Liu, H. Peng, Adv. Mater. 2018, in press, 1800996; Y. Zhang, L. Zhang, C.

Zhou, Accounts of Chemical Research 2013, 46, 2329; H. Moriguchi, H. Ohara, M. Tsujioka, History and Applications of Diamond-Like Carbon Manufacturing Processes, Sumitomo

Electric: sei technical review. 2016, 52; M. Kumar, Y. Ando, J. Nanosci. Nanotechnol. 2010, 10(6), 3739; M. L. Terranova V. Sessa, M. Rossi, Chem. Vapor Depos. 2006, 12, 315.

[10] Chemical Vapor Deposition, Eds. J-H Park, T. S. Sudarshan, Chapter 1, Introduction to Chemical Vapor Deposition (CVD), J. R. Creighton and P. Ho, ASM International, 2001

[11] N. G. Shang, Y. Y. Tan, V. Stolojan, P. Papakonstantinou, S. R. P. Silva, Nanotechnology 2010, 21, 505604

[12] Chemical Rubber Company Handbook of Chemistry and Physics. 97th ed (ed. W. M. Haynes) CRC Press, 2015.

[13] M. Ahmad, J. Anguita, V. Stolojan, T. Corless, J-S. Chen, J. D. Carey, S. R. P. Silva, Adv. Funct. Mater. 2015, 25, 4419; Y. Y. Tan, K. D. G. I. Jayawardena, A. A. D. T. Adikaari, L. W. Tan, J. V. Anguita, S. J. Henley, V. Stolojan, J. D. Carey, S. R. P. Silva, Carbon 2012, $50,668$.

[14] J. Huang, D. Fam, Q. He, H. Chen, D. Zhan, S. H. Faulkner, M. A. Nimmo, A. I. Y. Tok, J. Mater. Chem. C 2014, 2, 109.

[15] F. P. Bundy, W. A. Bassett, M. S. Weathers, R. J. Hemley, H. K. Mao, A. F. Goncharov, Carbon 1996, 34, 141.

[16] A. C. Ferrari, J. C. Meyer, V. Scardaci, C. Casiraghi, M. Lazzeri, F. Mauri, S. Piscanec,

D. Jiang, K. S. Novoselov, S. Roth, A. K. Geim, Phys. Rev. Lett. 2006, 97, 187401.

[17] A. C. Ferrari, J. Robertson, Phys. Rev. B 2000, 61, 14095.

[18] F. Tuinstra, J. L. Koenig, J. Chem. Phys. 1970, 53, 1126. 


\section{WILEY-VCH}

[19] R. S. Weatherup, L. D’Arsié, A. Cabrero-Vilatela, S. Caneva, R. Blume, J. Robertson, R. Schloegl, S. Hofmann, J Am. Chem. Soc. 2015, 137, 14358; S. Weatherup, B. C. Bayer, R. Blume, C. Baehtz, P. R. Kidambi, M. Fouquet, C. T. Wirth, R. Schlögl, S. Hofmann, ChemPhysChem. 2012, 13, 2544; B. Dlubak, M.-B. Martin, R. S. Weatherup, H. Yang, C. Deranlot, R. Blume, R. Schloegl, A. Fert, A. Anane, S. Hofmann, P. Seneor, J. Robertson, ACS Nano. 2012, 6, 10930.

[20] A. N. Obraztsov, E. A. Obraztsova, A. V. Tyurnina, A. A. Zolotukhin, Carbon 2007, 45, 2017.

[21] M. Escobar, M. S. Moreno, R. J. Candal, M. C. Marchi, A. Caso, P. I. Polosecki, G. H. Rubiolo, S. Goyanes, Appl. Surf. Sci. 2007, 254, 251; J. Kong, A. M. Cassell, H. Dai, Chem. Phys. Lett. 1998, 292, 567.

[22] N. Weidler, J. Schuch, F. Knaus, P. Stenner, S. Hoch, A. Maljusch, R. Schäfer, B. Kaiser, W. Jaegermann, J. Phys. Chem. C. 2017, 121, 6455.

[23] Fuel Cell Technologies Program Multi-Year Research, Development and Demonstration Plan, United States Department of Energy,

\section{https://www.energy.gov/eere/fuelcells/downloads/fuel-cell-technologies-office-multi-year-}

\section{research-development-and-22, 2012.}

[24] N.-W. Pu, G.-N. Shi, Y.-M. Liu, X. Sun, J.-K. Chang, C.-L. Sun, M.-D. Ger, C.-Y. Chen, P.-C. Wang, Y.-Y. Peng, C.-H. Wu, S. Lawes, J. Power Sources 2015, 282, 248.

[25] A. C. Stoot, L. Camilli, S.-A. Spiegelhauer, F. Yu, P. Bøggild, J. Power Sources 2015, 293, 846; C.-Y. Chung, S.-K. Chen, P.-J. Chiu, M.-H. Chang, T.-T. Hung, T.-H. Ko, J. Power Sources 2008, 176, 276.

[26] J-H. Chen, C. Jang, S. Xiao, M. Ishigami, M.S. Fuhrer, Nat. Nano 2008, 3, 206.

[27] J. Sudagar, J. Lian, W. Sha, J. Alloy. Compd. 2013, 571, 183.

[28] D. L. Nika, A. A. Balandin, Rep. Prog. Phys., 2017, 80, 306502; A. Li, C. Zhang, Y-F. Zhang, Polymers 2017, 9, 437; W. Lee, K. D. Kihm, H. G. Kim, S. Shin, C. Lee, J. S. Park, S. 


\section{WILEY-VCH}

Cheon, O. M. Kwon, G. Lim, W. Lee, Nano Lett. 2017, 17, 2361; A. A. Balandin, Nat. Mater. 2011, 10, 569; A. A. Balandin, S. Ghosh, W. Bao, I. Calizo, D. Teweldebrhan, F. Miao, C.N. Lau, Nano Lett. 2008, 8, 902.

[29] H. Wang, M. A. Sweikart, J. A. Turner, J. Power Sources 2003, 115, 243; D. P. Davies,

P. L Adcock, M Turpin, S. J Rowen, J. Power Sources 2000, 86, 237. 


\section{WILEY-VCH}

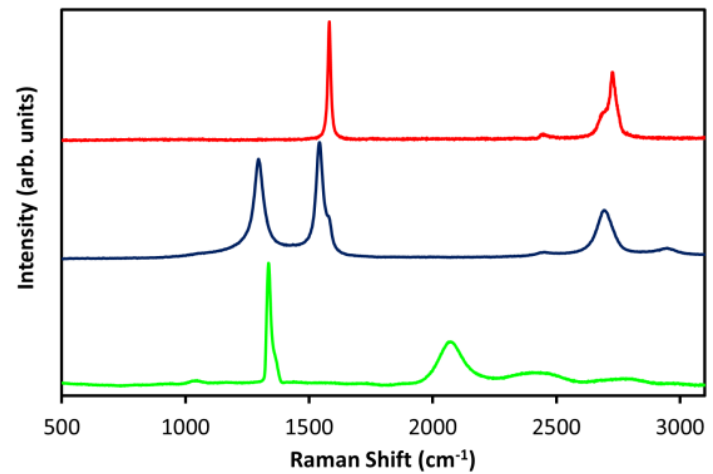

Figure 1 Normalised Raman spectra of (red line - top) HOPG, (blue line - middle) graphitic carbon coated nickel plated steel, and (green line - bottom) diamond.
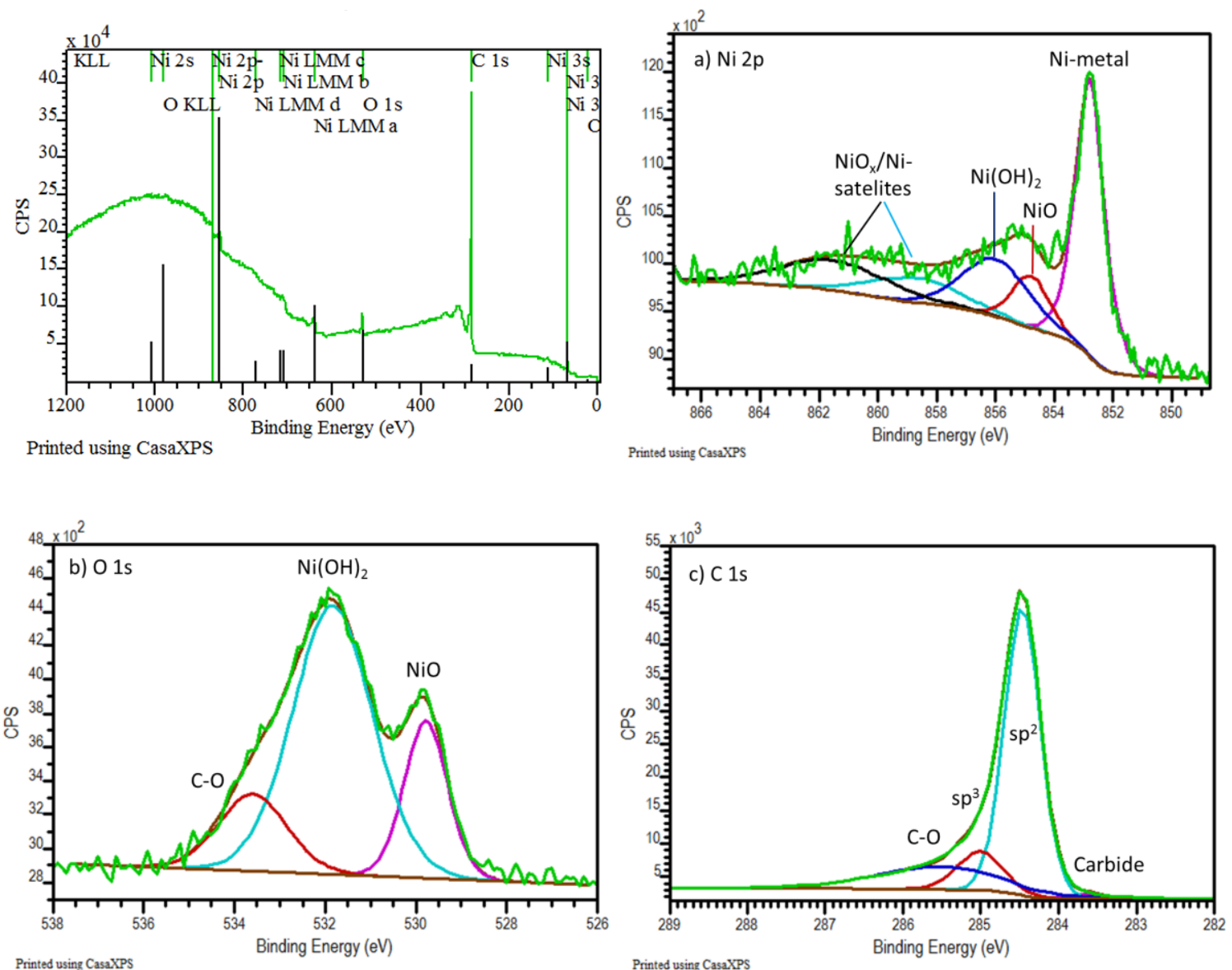

Figure 2 XPS spectra of the graphitic carbon coated nickel plated steel and magnified sections of (a) Ni 2p, (b) O 1s and (c) C 1s. 


\section{WILEY-VCH}
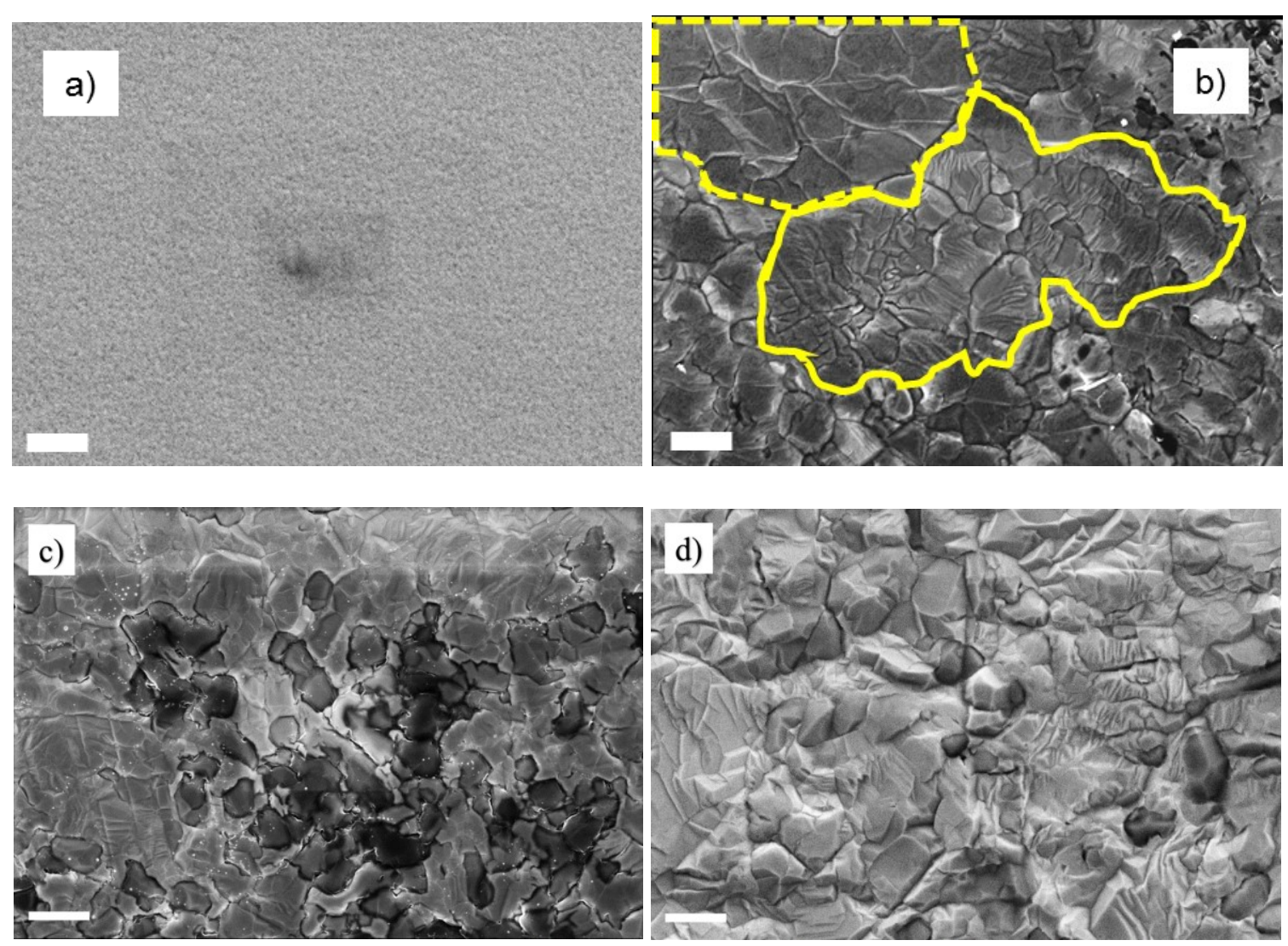

Figure 3 SEM images of (a) the oxidized surface of the uncoated nickel plated steel, and (b-d)

carbon coated nickel plated steel. (b) shows two areas with (solid line) and without (dashed line) crystal terracing visible in the domains. (c and d) show a comparison of the carbon coating on the rear and front sides of the substrate respectively. [scale bars $=1 \mu \mathrm{m}$ ]

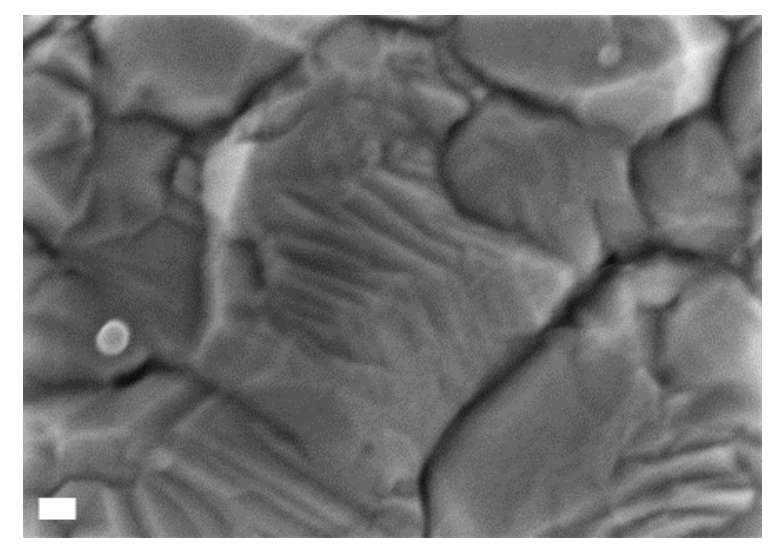

Figure 4 High magnification SEM image of the carbon coated nickel plated steel [scale bar = $100 \mathrm{~nm}]$ 


\section{WILEY-VCH}

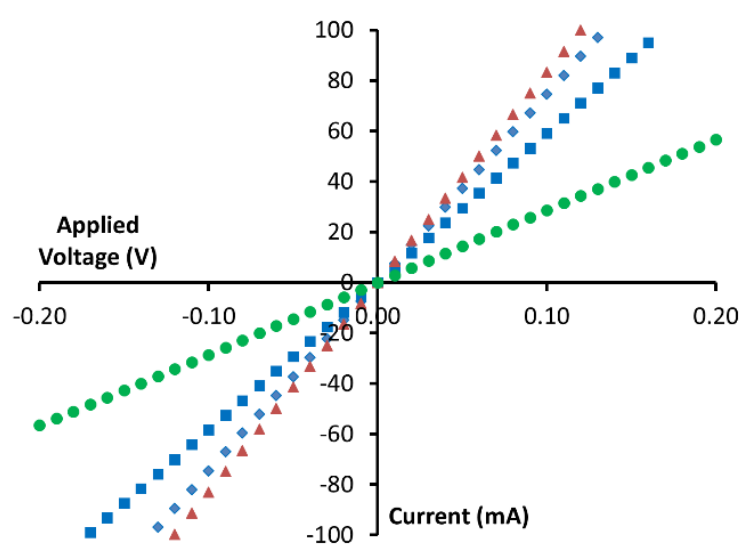

Figure 5 Current-voltage curves for (green circles) stainless steel, the (blue squares) rear and (blue diamonds) top surfaces of the nickel plated steel, and (red triangles) graphitic carbon coating on the top surface of the nickel plated steel.

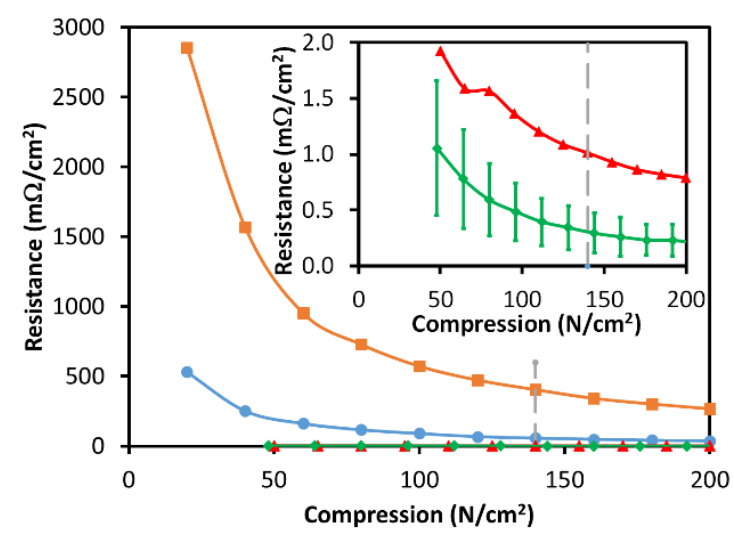

Figure 6 Interfacial contact resistance of: uncoated stainless steel (orange squares); nickel plated steel (blue circles); gold coated stainless steel (red triangles); and carbon coated nickel plated steel (green diamonds). The inset magnified graph gives the latter datasets in more detail. The data for the carbon coated nickel plated steel gives the mean and standard deviation of measurements for 4 samples. The dashed vertical line in each graph gives the DoE measurement pressure for contact resistance $\left(140 \mathrm{~N} \mathrm{~cm}^{-2}\right)$ for fuel cell bipolar plates. ${ }^{[20]}$ 


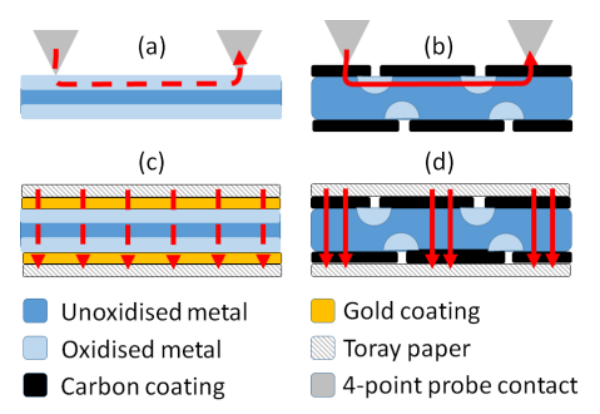

Figure 7 Electrical conduction paths (red arrows) in 4-point probe measurements through (a) oxidized uncoated steel and (b) through graphitic carbon coated nickel plated steel, and in ICR measurements through (c) gold coated stainless steel and (d) graphitic carbon coated nickel plated steel.
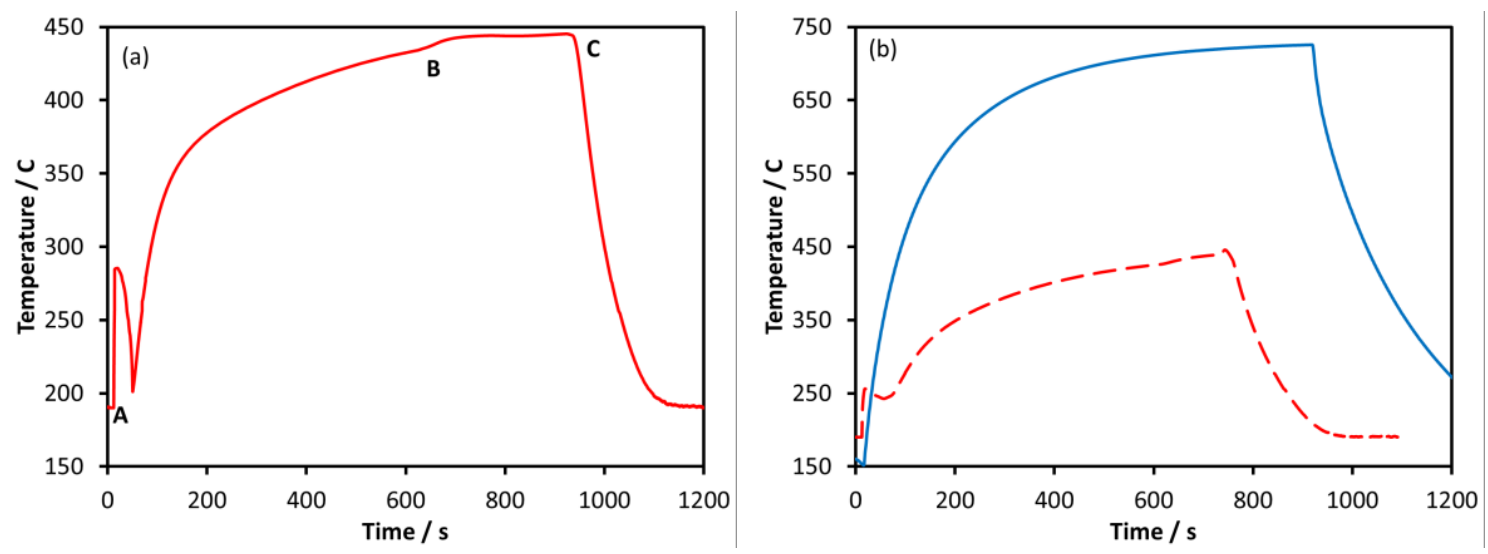

Figure 8 (a) Example temperature curve, recorded on the rear of the steel substrate using the pyrometer, for carbon growth on steel using $50 \%$ halogen lamp power $(4 \mathrm{~kW}) . \mathrm{A}=$ halogen lamps illuminated, $\mathrm{B}=$ ethylene introduction, $\mathrm{C}=$ halogen lamps extinguished. (b) Comparative temperatures on the upper (solid line) and reverse (dashed line) sides of a substrate, recorded by a thermocouple and pyrometer respectively, during heating at $50 \%$ halogen lamp power $(4 \mathrm{~kW})$. 
Table 1 Example Raman peak parameters taken from Figure 1.

\begin{tabular}{lcccccccccc}
\hline Material & \multicolumn{3}{c}{ Peak Position $\left[\mathbf{c m}^{-1}\right]$} & \multicolumn{2}{c}{ FWHM } & {$\left[\mathbf{c m}^{-1}\right]$} & \multicolumn{2}{c}{ Ratios } & \multicolumn{2}{c}{ Defect spacing [nm] } \\
& $\mathbf{D}$ & $\mathbf{G}$ & $\mathbf{2 D}$ & $\mathbf{D}$ & $\mathbf{G}$ & $\mathbf{2 D}$ & $\mathbf{I}_{\mathbf{D}} / \mathbf{l}_{\mathbf{G}}$ & $\mathbf{I}_{\mathbf{2 D}} / \mathbf{l}_{\mathbf{G}}$ & La' a) $^{\text {a }}$ & La $^{\mathbf{b})}$ \\
\hline Carbon coated nickel plated steel & 1347 & 1584 & 2694 & 47 & 35 & 74 & 0.85 & 0.39 & 1.25 & 5.17 \\
\hline
\end{tabular}

a) $\mathrm{La}^{\prime}=$ approx. inter-defect distance $\left(\mathrm{I}_{\mathrm{D}} / \mathrm{I}_{\mathrm{G}}=\mathrm{C}^{\prime}(\lambda) \mathrm{La}^{\prime 2} \text {, where } \mathrm{C}^{\prime}(514 \mathrm{~nm}) \sim 0.0055 \AA\right)^{[15]}$

b) $\mathrm{La}=$ approx. inter-defect distance $\left(\mathrm{I}_{\mathrm{D}} / \mathrm{I}_{\mathrm{G}}=\mathrm{C}(\lambda) \mathrm{La} \text {, where } \mathrm{C}(514 \mathrm{~nm}) \sim 0.44 \AA\right)^{[16]}$

Table 2 Sheet resistance values calculated from Figure 5.

\begin{tabular}{|c|c|c|}
\hline Material & Slope $\left[\mathrm{mA} \mathrm{V}^{-1}\right]^{\mathrm{a})}$ & $R_{\mathrm{sh}}\left[\mathrm{m} \Omega \square^{-1}\right]$ \\
\hline Stainless steel & 286.46 & 7.32 \\
\hline Nickel plated steel (rear surface $-0.6 \mu \mathrm{m}$ nickel plating) & 587.56 & 3.57 \\
\hline Nickel plated steel (top surface $-2 \mu \mathrm{m}$ nickel plating) & 745.56 & 2.81 \\
\hline Graphitic carbon coated nickel plated steel (top surface) & 831.55 & 2.52 \\
\hline
\end{tabular}

a) Probe separation $(\mathrm{s})=0.636 \mathrm{~mm}(25 \mathrm{mils})$

Table 3 Interfacial contact resistance at $140 \mathrm{~N} \mathrm{~cm}^{-2}$, taken from Figure 6.

\begin{tabular}{|c|c|}
\hline Material & ICR $\left[\mathrm{m} \Omega \mathrm{cm}^{-2}\right]$ at $140 \mathrm{~N} \mathrm{~cm}^{-2}$ \\
\hline Bare stainless steel & 388.00 \\
\hline steel & 61.00 \\
\hline Gold coated stainless steel & 1.01 \\
\hline Graphitic carbon coated nickel plated steel & $\sim 0.30$ \\
\hline
\end{tabular}

Table 4 Electrical conductivity $(\sigma)$ values for the experimental steel samples and comparative values for selected steels and graphitic carbons taken from the literature

\begin{tabular}{|c|c|c|c|c|}
\hline \multirow[t]{2}{*}{ Material } & \multicolumn{2}{|c|}{$\sigma\left[\mathrm{S} \mathrm{m}^{-1}\right]$ at $20^{\circ} \mathrm{C}$} & \multirow{2}{*}{$\begin{array}{l}\text { Orientation } \\
\text { to the basal plane }\end{array}$} & \multirow[t]{2}{*}{ Ref } \\
\hline & Experimental & Literature & & \\
\hline Graphene & & $\begin{array}{r}1.0 \times 10^{8} \\
\sim 1.0 \times 10^{2}\end{array}$ & \begin{tabular}{c||l} 
Parallel & \\
Perpendicular $\perp$
\end{tabular} & [26] \\
\hline Gold & & $4.5 \times 10^{7}$ & & [10] \\
\hline Nickel & & $1.0 \times 10^{7}$ & & [10] \\
\hline Carbon steel (1020) & $4.2 \times 10^{5}$ & $5.5 \times 10^{6}$ & & [10] \\
\hline Stainless steel & $4.3 \times 10^{5}$ & $1.4 \times 10^{6}$ & & [10] \\
\hline Carbon coated nickel plated steel & $1.3 \times 10^{6}$ & & & \\
\hline Nickel plated mild steel & $4.8 \times 10^{5}$ & & & \\
\hline Graphite & & $2.0 \times 10^{5}$ & Parallel \| & [1] \\
\hline & & $3.3 \times 10^{2}$ & Perpendicular $\perp$ & [1] \\
\hline HOPG & & $2.5 \times 10^{6}$ & Parallel \| & [10] \\
\hline & & $6.7 \times 10^{2}$ & Perpendicular $\perp$ & [10] \\
\hline
\end{tabular}




\section{WILEY-VCH}

Table of contents entry:

The electrical properties of nickel plated steel are enhanced by the application a thin coating of graphitic carbon. Sheet resistance is improved by approximately $10 \%$ and interfacial contact resistance is reduced by 200 times. Such electrically conducting coated steel has potential for high end electrical applications such as energy storage and microelectronics.

\section{Keyword: Steel coatings}

C. A. Mills, * E. Batyrev, M. J. R. Jansen, M. Ahmad, T. S. Pathan, E. J. Legge, D. B. Thakur, S. N. Patole, D. J. L. Brett, P. R. Sheering, H. van der Weijde, and S. R. P. Silva

Improvement in the Electrical Properties of Nickel Plated Steel using Graphitic Carbon Coatings

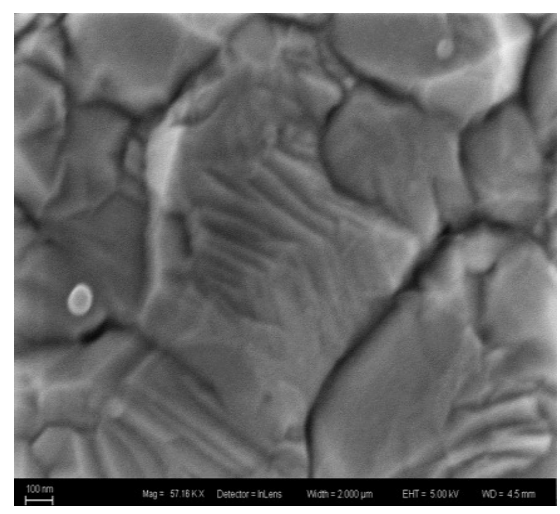

